\title{
Classical Measurement Methods and Laser Scanning Usage in Shaft Hoist Assembly Inventory
}

\author{
Wojciech Jaśkowski ${ }^{1,}{ }^{*}$, Tomasz Lipecki ${ }^{1}$, Wojciech Matwij ${ }^{1}$, Mateusz Jabłoński ${ }^{1}$ \\ ${ }^{1}$ AGH University of Science and Technology, Faculty of Mine Surveying and Environmental \\ Engineering, A. Mickiewicza Av. 30, 30-059 Krakow, Poland
}

\begin{abstract}
The shaft hoist assembly is the base of underground mining plant. Its efficiency and correct operation is subject to restrictive legal regulations and is controlled on a daily visual assessment by shaft crew and energomechanics. In addition, in the regular interval, the shaft hoist assembly is subject to a thorough inventory, which includes the determination of the geometrical relationships between the hoisting machine, the headframe and the shaft with its housing. Inventory measurements for shaft and headframe are used for years of conventional geodetic methods including mechanical or laser plumbing and tachymetric surveys. Additional precision levelling is also used for measuring shafts of hoisting machines and rope pulleys. Continuous modernization of measuring technology makes it possible to implement the further methods to the above mentioned purposes. The comparison of the accuracy and the economics of performing measurements based on many years of experience with comprehensive inventory of shaft hoist assembly using various research techniques was made and detailed in the article. Key words - headframe, shaft, laser scanning, survey economics.
\end{abstract}

\section{Introduction}

The article presents an analysis of the inventory measurements of symmetric double strut headframe construction and two hoisting machines (Fig. 1). The headframe is located above a 160-meter shaft and equipped with two rope pulleys platforms, located at a height of $37 \mathrm{~m}$ and $43.7 \mathrm{~m}$ above the framework of the shaft. At the bottom level there are three overturned rope pulleys, including two on one side (A) and one on the other (B). Above the single one there is located another one on upper platform (B).

The spatial distribution between elements of the headframe, shaft and hoisting machine elements is variable over time. Changes in the location are caused by mining works, mining tremors, weather conditions (sunlight, wind) and impact of the lifting equipment on the headframe construction [1]. The detailed rules (shown below) related to the Geological-Mining Law as parameters of safe transport of the shaft indicate: the verticality of the headframe's stem, the inclination of the rope pulleys and the hoisting machine drum, actual values of friction angles and values of clearance in the mining shaft.

* Corresponding author: jaskow@agh.edu.pl 


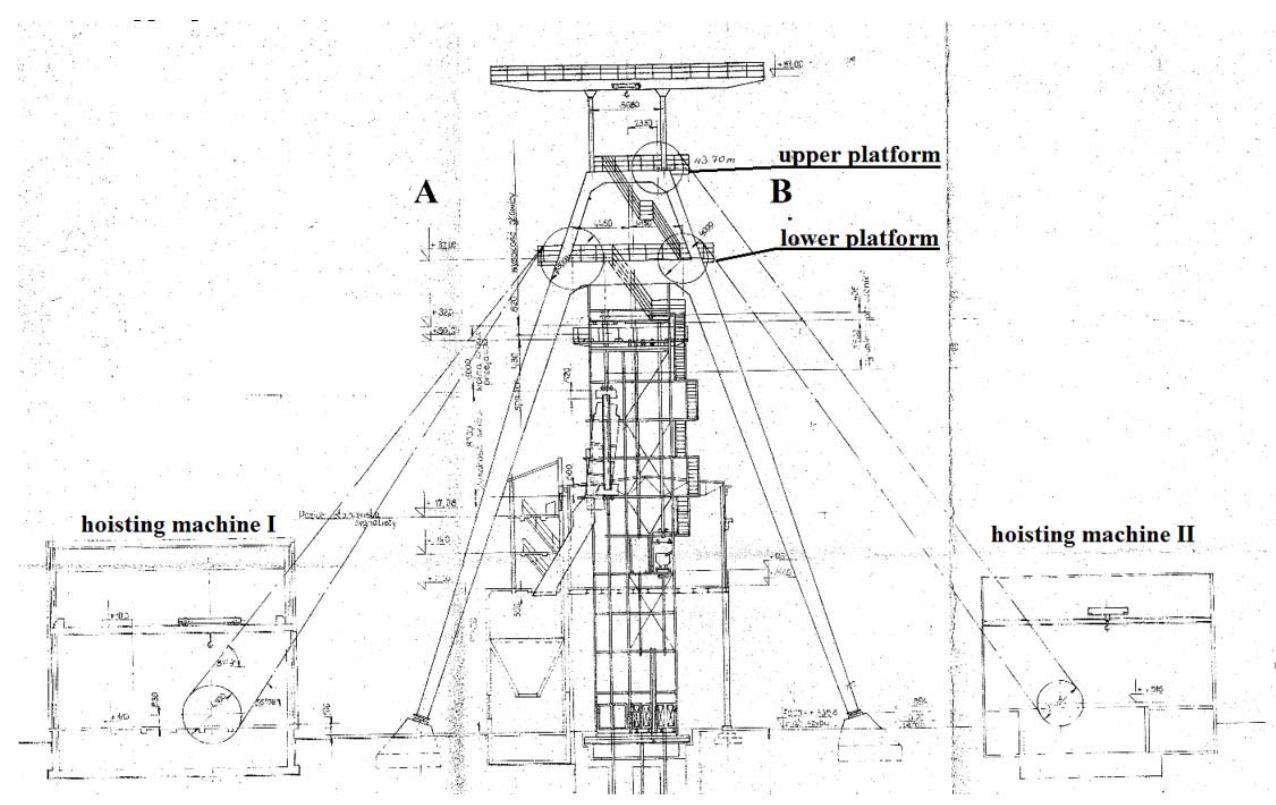

Fig. 1. Construction scheme of headframe

\section{Legal basis in Poland}

Principles of performing control measurements in Poland are regulated by following legal acts:

- Regulation of Minister of Energy from 23 November 2016 on detailed requiremenets for the operation of underground mining plants (Journal of Laws No. 1118, 2017, item 1),

- Polish Standard - Shafts, headframes and hoisting equipment (PN-G-09051) - p.1.2.91.2.14, p. 2.2.

In accordance with $\S 43$ section II of the Regulation, the mine and geological service of the mining should carry out inventory and control measurements of mining excavations and equipment, and objects of the mining plant during traffic and decommissioning, as well as observations of deformation of the land and buildings subject to the influence of mining exploitation. According to $\$ 29$ the group of buildings include shafts, headframes with buildings, hoisting machines and pithead buildings. The most important rule in the Regulation (\$542.2) refers to the headframe's verticality, which cannot exceed 1/500 of the headframe's height, measured from the axis of the top rope pulley to the framework. In practice, measurements determine inclination of the headframe at a certain section of this height - usually from framework or the lowest available level of the headframe, up to the level of the pulley platform and extrapolates to the height of the wheels axle. Further provisions also specify, among other things, permissible deviation of shafts of hoisting machines and rope pulleys, friction angles of ropes on the above-mentioned elements and permissible deviations from guide clearance $[2,3]$.

Almost all of the above regulations require very precise measurement at several millimetres. For example, for the analysed object, the height of the headframe from the beams to the axle of the upper rope pulleys is $44.8 \mathrm{~m}$. According to the regulations, its inclination should not exceed $89.6 \mathrm{~mm}$, which means that the measurement error on a $10 \mathrm{~mm}$ level can significantly affect the result of headframe's inclination. 


\section{Methodology of inventory measurement and analysis}

In order to determine the deviation vector of the main axis of the headframe from the verticality, the following geodetic methods can be used: optical and mechanical or laser plumbing, space resection, projection to the lower levels or checkpoints and characteristic points tachymetric measurement. These are discrete methods that define the state of the axis of the structure indirectly for one observation cycle $[4,5]$. In addition to the above methods, it is necessary to mention the need for precision levelling of the rope pulleys and hoisting machines shafts (to determine inclination of its axles).

In order to make a complete inventory of the mining shaft, a number of complementary measurement techniques should be used, which significantly increases the length of the survey. A collection of classic geodetic methods can be partially replaced by laser scanning, which allows surveyor to get as much information as possible in the shortest possible time. The scope of these data is incomparably greater than that obtained by traditional methods. In addition, the use of scanning can be important from an economic point of view as well as for the safety of the workers performing the measurements.

Modern surveying technologies in the form of 3D laser scanning surveys allow to perform analysis with so many measured points that the space mapped in discrete form looks real. Scanning measurements take a very short time (a few minutes at the station) and the amount of information thus obtained is impossible to get by other measurement methods. This enables analysis and digital modelling to be performed on any of a set of points that define the object components [6].

Inventory measurement was performed twice: in the first series in 2011, the precision tachymeter was used to measure the geometry of the headframe and in the second series in 2016 the terrestrial laser scanner (TLS) was used to measure the entire shaft hoist assembly system.

Due to the speed and accuracy of the measurements, as well as the lack of need to pause for long time operation of shaft equipment, the first series in 2011 was scheduled to perform measurements of angular-linear precision laser total station. Basic angular-linear measurements were focused on the characteristic points that were marked in accordance with the Regulation at various levels of the headrfame and the footings on each leg struts. These points should enable the capability of measuring the distance between them directly and should be elevated points, whose height should be determined together with the height of the benchmarks located at the struts base. The collection of points was transformed into a simplified headframe model and a deflection analysis was performed on this basis (Fig. 2).

a)

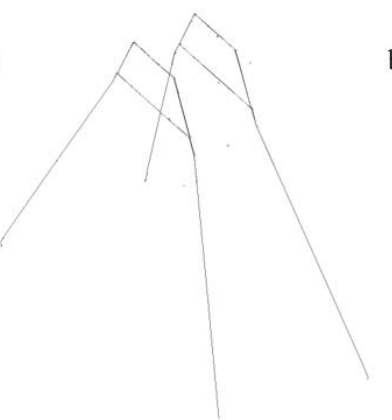

b)

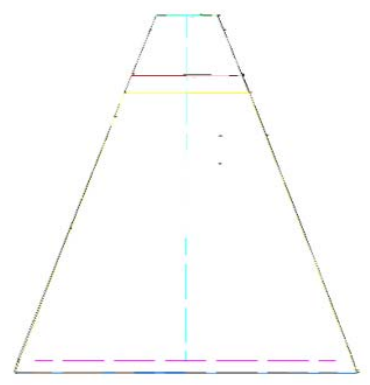

c)

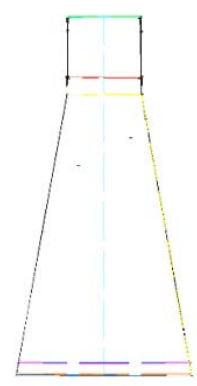

Fig. 2. (a) spatial view, (b) front view, (c) side view of the main axis of the headframe based on the control points, observations made in 2011

After the statutory five years, in 2016, the second series of measurements was carried out using a laser scanner Leica ScanStation C10 that allows obtaining information about the 
measured object with an accuracy of each point not worse than $\pm 6 \mathrm{~mm}$ for a single measurement scanner position [7]. For the measurement of the control-network, the connecting points of the scans (checkers) and for the control of the characteristic points, a precise tachymeter was used.

The second measurement series made in 2016 enabled cross-sections implication $[8,9]$ and more accurate indication of inclination changes in the vertical axis of the headframe. It also enabled creating a graph of changes in the headframe's deviation on individual sections. Test procedure is based on measurements of the headframe and its stem.

Based on the laser scanner's measurements, digital models of structures were created allowing for further numerical analyses. It consisted of determining the characteristic points located on the axes of the hoisting machines, determining the transverse profiles at the level of the girders at intervals of $4 \mathrm{~m}$, and determining the coordinates of the points representing the established levels and respective planes of the rigid guides and angular guides. The obtained data was used to develop the spatial arrangement of the drum axis of the machines and the rope pulleys, the straightness of the guides and the angular guides, the determination of the guide clearance and the position relative to the rigid guides.

\section{Results of analysis}

The control-network was adjusted using the exact method, which allowed to designate junction points for scans with a mean position error of $\pm 2 \mathrm{~mm}$. As a result, a single point error was less than $10 \mathrm{~mm}$. Conversion to the global system was allowed by static GNSS measurement performed on control network positions [9]. The measurement product of the second series was a cloud of points representing the structure of headframe and hoisting machine (Fig. 3). The verticality is determined by analysing digital spatial model of the object. Measurement done with the above accuracy is quite sufficient to determine the position of characteristic points, later used to determine the symmetry centres of appropriate levels of the object or its fragments.


Fig. 3. Point cloud representing the (a) headframe and (b) hoisting machine. P1, P2, N1, N2 - points where line slides off from the hoisting machine's drum

Based on point cloud cross-sections of headframe's stem were made (Fig. 4a, b). It allowed to calculate their centres and what enabled to create a graph of changes in the headframe's 
deviation on individual sections. The goal is to designate the vector length direction and the horizontal pivot axis of the headframe (Fig. 4c).

a)

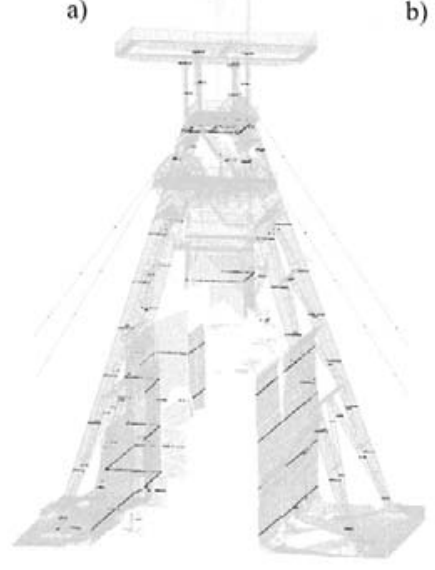

b)

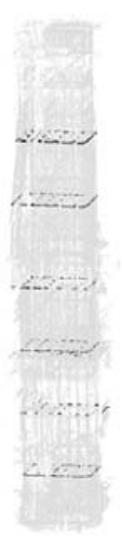

c)

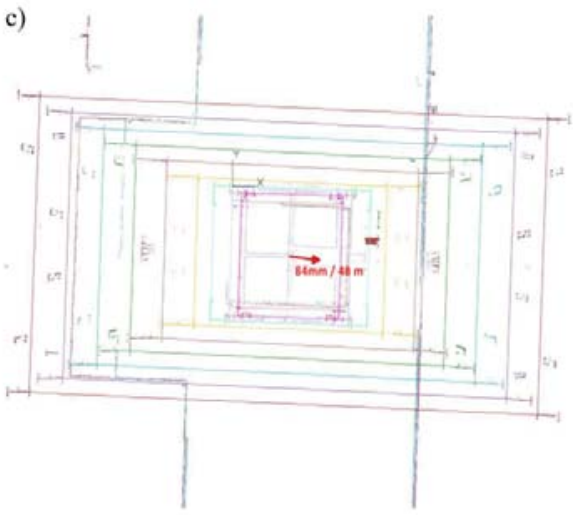

Fig. 4. Point cloud of the (a) headframe and (b) its stem (cross-sections marked with black); (c) top view of cross-sections with marked vector of inclination (status for 2016)

a)

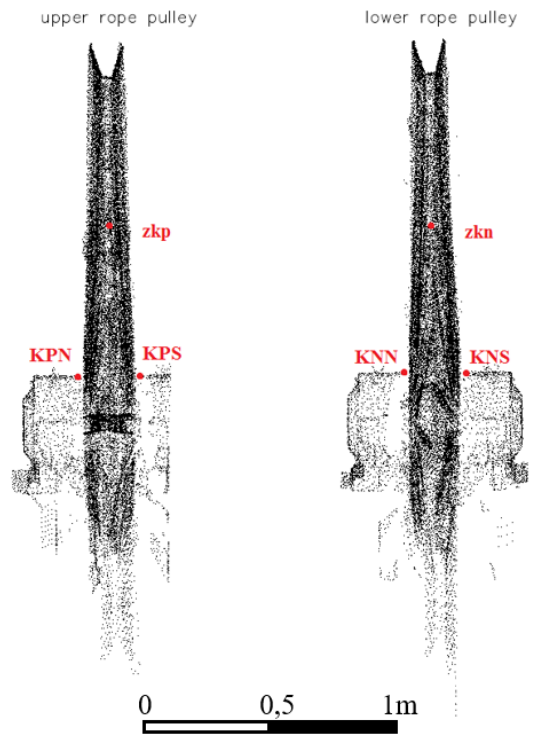

ROPE PULLEYS PRECISE LEVELLING RESULTS

b) upper rope pulley

lower rope pulley
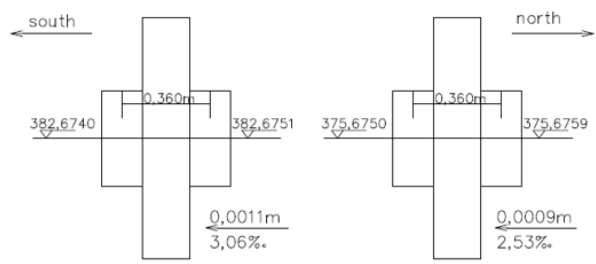

from east.

HOISTING MACHINE PRECISE LEVELLING RESULTS

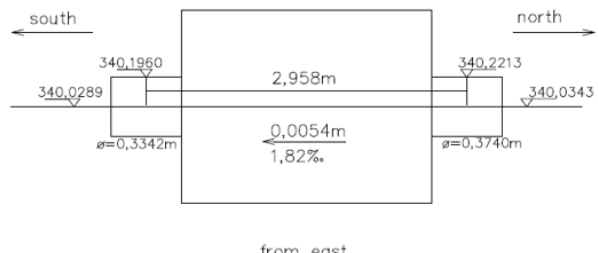

Fig. 5. View of the point clouds (a) of the rope pulleys together with the marking of the levelling points (KPN, KPS, KNN, KNS) and points where rope slides from the pulleys (zkp, zkn); (b) an example view of the results obtained (2016)

Scanning data was also used to determine the spatial relationship between the rope pulleys and hoisting machines and the verticality of the rope coming down into the shaft (Fig. 5). The points where the rope slides from the pulleys and the hoisting machines drums allowed to calculate the actual friction angles. The hoisting machine's drum width was determined by two methods: classically by tachymeter and by a laser scanner. The analysis showed a difference of several millimetres, which has no real effect on the results obtained, and falls within the accuracy of the measurement with both methods. Data from the precise 
levelling of the shafts of the wheels and hoisting machines were obtained with the help of a precision levelling. This data was also compared with the results from point cloud analysis and also differences in data accuracy have been reported. The cloud of points has information about the height up to few millimetres, precise levelling is much more accurate. Due to the fact that width of the pulleys is between $0,3-0,4 \mathrm{~m}$, precision of measurement is becoming more important (Fig. 5).

In the second series scanning measurement was extended of shaft. Measurement were performed there from the roof of shaft cage. To register scans spheres were used as target points, allowing for measurement without time-consuming mechanical plumbing, saving several hours of shutting down the shaft for the measurement period (Fig. 6).

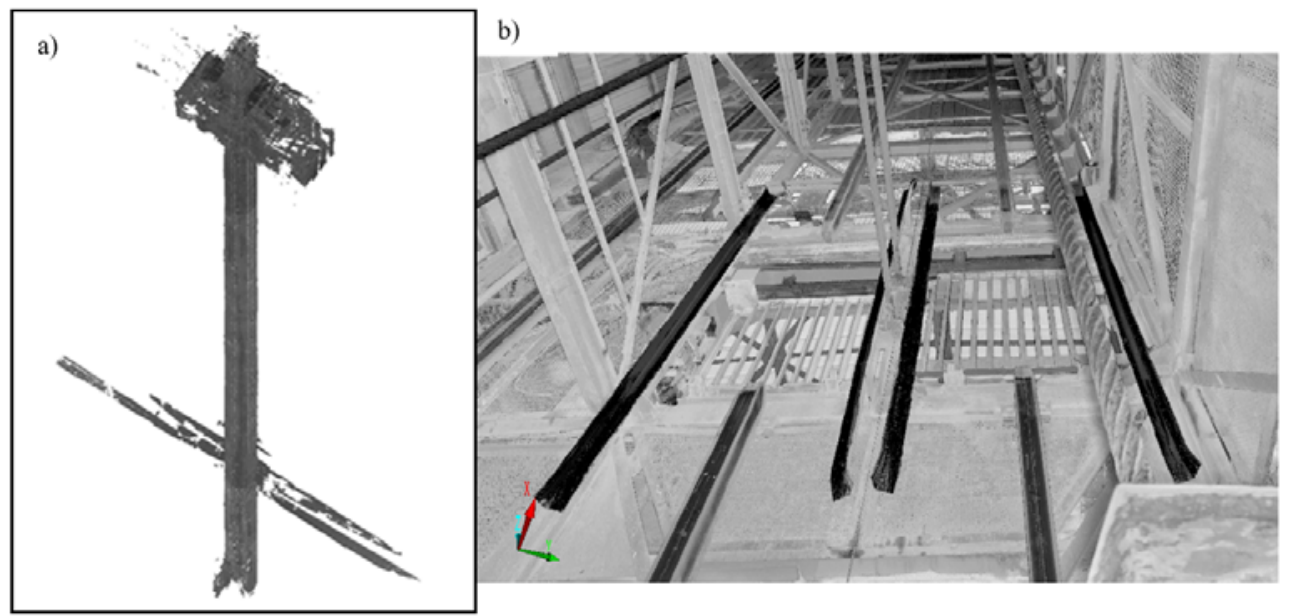

Fig. 6. Point clouds representing (a) the entire shaft with (b) its equipment

This enabled an analysis of guiding clearance and angular guiding in the shaft (Fig. 7), and the determination of the characteristic points needed to determine the verticality of the rope coming down the shaft, and the apparent and actual friction angles. Based on point cloud also the deviation of shaft verticality graph could be done.
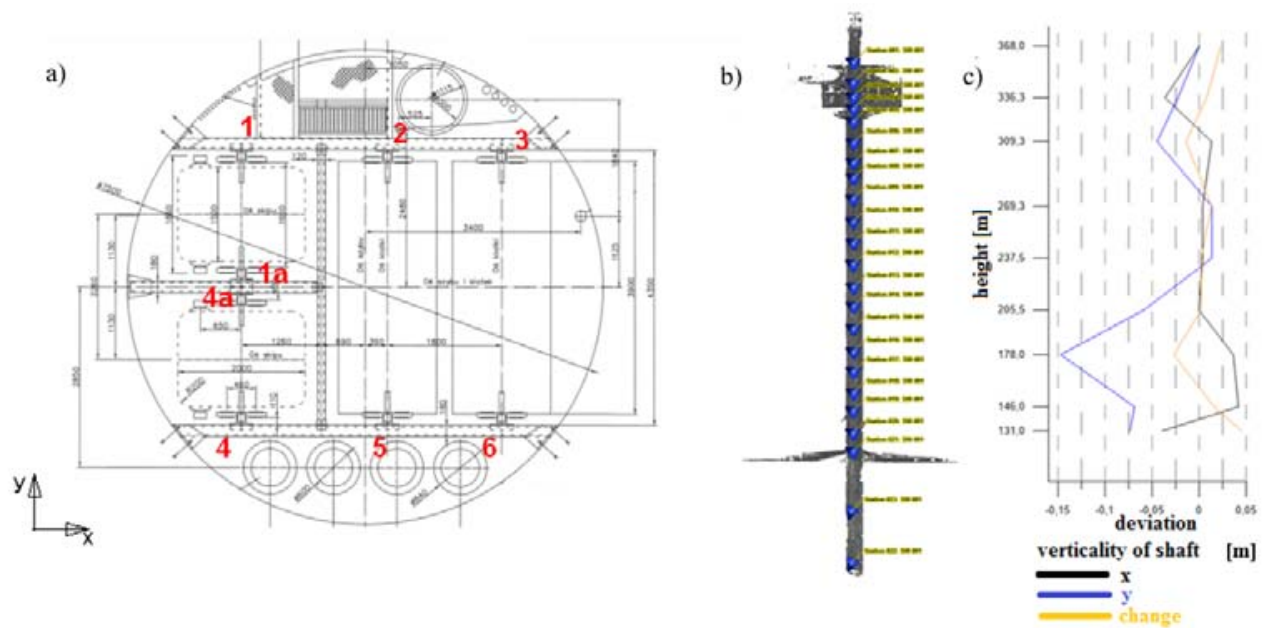

Fig. 7. (a) schematic diagram of the shaft with marked guides (in red), top view; (b) positions of the laser scanner in the shaft; (c) graph showing the verticality of the axis of the shaft 


\section{Conclusions}

The accuracy of a single point in the point cloud is estimated to be less than $10 \mathrm{~mm}$. This is sufficient in the case of the implementation of the profiles and the calculation of the course of the main axes and guide planes. For the shaft hoist assembly (divided into the westskip and east machine) the azimuth graphs of ropes, rope pulleys and hoisting machine shafts axes, angles of friction, inclination of shafts and verticality of descent rope to the mining shaft from the level of the rope pulleys were created. During measurements nominal spacing for individual shaft compartments (east and west) and the width and length of vessels along with sliding were also designated.

Measurement of the entire hoist assembly: shaft, headframe with its stem and hoisting machine, four people team completed in about 12 hours, including control measures allowing to check the usefulness of scanning data to specific issues. Thanks to the use of laser scanning, the team was able to skip the most time-consuming tasks like mechanical plumbing in the shaft and the headframe. The tachymetric measurements was also partially eliminated. It is therefore possible to assume that the time taken to measure and thus to shut down the shaft from traffic has fallen by half. Working time, its nature and the number of people involved in the measurement also indicate an increase in safety of the measurement team.

Laser scanning becomes a very serious substitute for many measurement methods and complements the entire study. It shows how modern technologies get into the consciousness of surveying departments. However one should be aware of restrictions in the use of laser scanning in shaft conditions (for example high humidity or dust in the exhaust shafts). In addition, the availability of measuring equipment and time consuming data processing and performance of available computers can still be a problem for surveying departments. Data obtained from several dozen laser scanner stations require efficient graphics cards and large memory of computers, together with specialized knowledge of data processing.

\section{Acknowledgment}

This article was developed within the statutory work of AGH US 11.11.150.195.

\section{References}

1. Z. Szczerbowski, M. Jóźwik, Examples of natural and mining conditions of deformation of mining shaft (XXV Winter School of Highland Mechanics 'Geotechnics and Special Construction', Zakopane, (2002)

2. Regulation of Minister of Energy from 23 November 2016 on detailed requiremenets for the operation of underground mining plants (Journal of Laws No. 1118, 2017, item 1)

3. T. Lipecki: A comprehensive assessment of geometric objects and shaft devices using laser scanning (Akademia Górniczo-Hutnicza in. Stanisława Staszica w Krakowie, ISBN: 987-83-7464-602-4

4. J. Pielok: Inventory of Pomerania mine shafts (Monthly WUG, No. 3, (2004)

5. M. Jabłoński, W. Jaśkowski, The usage of telemetry measurement methods in order to determine shaft tube deformations (SGEM 2017 conference proceedings, 17, 697-704, (2017)

6. B. Collin, P. Carreaud, H. Lancon, High efficiency techniques for the assessment of railways infrastractures and buildings (Transportation Research Procedia 14, pp. 1865-1874, (2016)

7. Leica Geosystems AG, Leica ScanStation C10 specification, (www.leica-geosystems.com/hds, Heerbrugg, Switzerland) 
8. M. Pejić, Design and optimisation of laser scanning for tunnels geometry inspection (Tunnelling and Underground Space Technology 37, pp. 199-206, (2013)

9. W. Wang, W. Zhao, L. Huang, V. Vimarlund, Z. Wang, Application of terrestrial laser scanning for tunnels: a review (Journal of Traffic and Transportation Engineering, 1(5), pp. 325-337, (2014) 